\title{
POLÍTICAS LINGÜÍSTICAS HACIA LA NUEVA ESPAÑA EN EL SIGLO XVIII*
}

Las modificaciones y cambios que la Corona española impuso en las políticas lingüísticas durante el siglo xvıI en la Nueva España, son de fundamental importancia para entender cómo quedaron configuradas las prácticas que serían características desde los comienzos del México independiente hasta nuestros días. Aunque desde el inicio de la conquista española los Reyes Católicos, pensaban que la imposición lingüística del castellano era uno de los medios más importantes para que pudiera afianzarse el poder de la Corona en el Nuevo Mundo, de la misma manera que se estaba imponiendo en la Península ibérica, las situaciones que día a día fueron enfrentando conquistadores y colonizadores los obligaron a adoptar políticas muy distintas. La amplia gama de estas políticas fue tan grande que en algunas circunstancias resultaron radicalmente opuestas. En posiciones extremas encontramos desde la prohibición de que los indígenas hablaran sus propias lenguas hasta la prohibición de que aprendieran español.

Como es natural, las políticas lingüísticas y educativas que fue adoptando la Corona constituyeron uno de los factores determinantes en la conformación de la sociedad y en el muy peculiar desarrollo cultural y aun científico del nuevo continente. Hay que tener presente, además, que en la Nueva España el mestizaje no sólo fue biológico, sino también cultural.

Tengamos en cuenta que, desde los inicios de la colonización española, Isabel y Fernando al consolidar la Reconquista con la toma de Granada habían identificado cristianizar con castellanizar. En la obra del filólogo humanista, Elio Antonio de Nebrija,

* Una primera versión de este artículo fue presentada en el "Seminario de España y América en la Monarquía de Carlos III", celebrado en Madrid del 3 al 7 de octubre de 1988, organizado por el Centro Español de Estudios de América Latina del Instituto de Cooperación Iberoamericana. 
se cristaliza y difunde una idea propia del naciente estado español, de que el poderío político de un pueblo está estrechamente unido a la imposición y la hegemonía de su lengua. Del muy conocido prólogo de la Gramática castellana de Nebrija el párrafo inicial muchas veces citado dice: " . . . siempre la lengua fue compañera del imperio; e de tal manera lo siguió, que juntamente començaron, crecieron e florecieron, e después junta fue la caída de entrambos"'. Recordemos que Nebrija contribuyó con su pionera gramática y con su diccionario latín-castellano a hacer del castellano una lengua de prestigio, de cultura y de poder y a darle un carácter nacionalista que desde entonces se enfrentó al mosaico dialectal y a las otras lenguas, que también alcanzaron prestigio dentro de la Península ibérica, como el catalán, el gallego y el vasco.

De la situación en el otro lado del Atlántico, debemos recordar que los españoles en la conquista de México no se encontraron con pueblos aislados sino que tuvieron que enfrentarse a una forma particular de imperio ya constituido por los aztecas. En el siglo XVI en Mesoamérica, es decir, en las zonas que hoy ocupan México y Guatemala, florecían o habían florecido a lo largo de tres mil años muchas de las culturas más avanzadas y refinadas de todo el continente americano, como la teotihuacana, la maya, la zapoteca, la mixteca, la tolteca y la que en el momento de la llegada de los españoles dominaba a casi todas las demás: la mexica. Fácilmente podemos calificar hoy a los nahuas, mexicas o aztecas como la nación imperialista de Mesoamérica. Hay que destacar que los mexicas, tan ajenos a las políticas lingüísticas del Renacimiento europeo, habían aplicado ellos mismos en la práctica algo similar a la conquista lingüística propuesta por Nebrija. En los albores del siglo xv los aztecas dominaban a la mayoría de los pueblos de Mesoamérica, todos ellos muy diferenciados lingüísticamente. Durante el siglo xv el náhuatl, como lengua del imperio mexica fue usado en toda la zona conquistada primero como lingua franca. Después, conforme la conquista guerrera dejaba paso a la colonización azteca que imponía nuevas formas de sujeción, el náhuatl se empezó a imponer como lengua oficial en todo el imperio y fue adquiriendo prestigio como lengua de poder y de cultura ${ }^{2}$.

${ }^{1}$ Nebr ija 1984. Sobre el pensamiento de Nebrija, y en general para las ideas políticas lingüísticas de los siglos XVI y XVII, véase BAHNER 1966.

${ }^{2}$ Dice Shirley Brice Heath que una de las hazañas más notables del dominio azteca sobre muchos pueblos indígenas fue "el establecimiento del ná- 
Los españoles se enfrentaron a grandes diferencias lingüísticas, infinitamente más complejas que las de la Península ibérica, y a pueblos cuyos niveles culturales eran muy altos, aunque radicalmente diferentes a los suyos. Para dar una idea de la complejidad y la variedad de lenguas que se hablaban en Mesoamérica, téngase en cuenta que en esa región existían, y aún subsisten, trece familias lingüísticas distintas ${ }^{3}$. Se designa como familia o como tronco al conjunto de hablas que deriva de una protolengua cuya diversificación se inició entre 3000 y 2000 años antes de nuestra era. Es decir, el término familias correspondería en la clasificación de las lenguas de Europa, de acuerdo con la distancia en tiempo, de mayor o menor cercanía entre unas y otras lenguas, a todo lo agrupado bajo el rubro de la protolengua indoeuropeo. En Europa, como se sabe, la mayoría de las lenguas, excepto el vasco, pertenecen a la familia o tronco indoeuropeo. En cambio, en $\mathrm{Me}$ soamérica, que fue el paso de todas las migraciones hacia el sur del continente, la diversidad lingüística era y sigue siendo mucho mayor.

Dados estos antecedentes lingüísticos prehispánicos, podemos comprender mejor que cuando los conquistadores españoles a su llegada encontraron el náhuatl extendido por todo el imperio ${ }^{4}$, vieran en este proceso hegemónico de la lengua náhuatl una situación relativamente fácil de conservar para resolver el problema de la diversidd lingüística que caracterizaba a Mesoamérica

huatl como lengua oficial del Imperio. Los aztecas adiestraban a los miembros de sus propias tribus, preparándolos para que fueran escribanos o intérpretes del náhuatl en todo lo relacionado con los asuntos administrativos del sistema tributario [...] El ser miembro de la cerrada y auténtica comunidad de idioma náhuatl proporcionaba a los [pueblos] dominados por los poderosos mexicas el derecho a la distinción política y a la dignidad social" (BRICE Heath 1972, pp. 18-20).

${ }^{3}$ Manrique 1988.

${ }^{4}$ Uno de los frailes historiadores, Jerónimo de Mendieta, que llegó treinta años después de iniciada la conquista, alababa a los aztecas por haber extendido el náhuatl como lengua común, de la misma manera como habían extendido el latín los romanos por Europa: "Esta lengua mexicana (náhuatl) es la general que corre por todas las provincias de esta Nueva España, puesto que hay muchas y diferentes lenguas particulares de cada provincia, y en partes de cada pueblo, porque son innumerables. Mas en todas partes hay intérpretes que entienden y hablan la mexicana, porque ésta es la que por todas partes corre, como la latina por todos los reinos de Europa", en su Historia Eclesiástica Indiana, t. 3 de la Nueva colección de documentos para la historia de México, recop. de Joaquín García Icazbalceta (México, 1870, 5 ts.), citado por Brice Heath 1972 , p. 21, nota 5. 
y, finalmente, llegar a imponer la lengua castellana. A la preservación por los españoles del uso del náhuatl y de otras lenguas dominantes como vehículos de conquista y penetración contribuyó el hecho de que en otras partes de Mesoamérica hubiera otras dos lenguas que también funcionaban como lenguas francas: el maya en la península de Yucatán y el tarasco en el reino de $\mathrm{Mi}$ choacán. Ante esta situación, los conquistadores decidieron en un principio emplear sobre todo el náhuatl como idioma dominante, para organizar con facilidad la administración civil y religiosa, a través de una lengua que era conocida por la mayor parte de los nuevos súbditos, aunque no fuera la propia. Es decir, la política lingüística abruptamente impositiva no se aplicó literalmente en un principio en el caso de México, y de Hispanoamérica en general, aunque a fin de cuentas, como veremos, fue la que se impuso en el siglo xviII.

La diversidad lingüística de Mesoamérica y el enfrentamiento con culturas muy desarrolladas llevó a la Corona española a ensayar distintas políticas lingüísticas y educativas durante los tres siglos de la Colonia. En primer lugar, surgió la necesidad apremiante de describir las lenguas habladas mayoritariamente, con objeto de establecer una comunicación básica con los sometidos. Esta tarea correspondió a los frailes misioneros, cuya meta era cristianizar a los indios 5 .

Los misioneros aplicaron otra medida práctica y efectiva para consolidar la conquista: centraron toda su labor educativa en las minorías gobernantes indígenas para alcanzar más fácilmente la evangelización de las masas indias. Al mismo tiempo, la Corona española empezó a emitir leyes con objeto de que se castellanizara y se instruyera a los indígenas en la fe cristiana, por medio de la lectura y la escritura. Se pretendía con esto no sólo integrar a los indios a la religión cristiana sino integrarlos más plenamente al control de la monarquía española.

Desde 1550, Carlos I quiso terminar con la política de cristianización en la lengua materna indígena en un decreto dirigido a todos los frailes, en el que cuestionaba que incluso el más perfecto lenguaje de los indios fuera adecuado para explicar las escrituras. Silvio Zavala, gran historiador de estos temas, señala que aun-

${ }^{5}$ Como dice Gonzalo Aguirre Beltrán, "conquistadores y misioneros son términos de una misma ecuación en manos de la Corona española para alcanzar los propósitos de la dominación ecuménica', Aguirre Beltrán 1983, p. 30. 
que Carlos I tuvo constantes opositores entre los frailes, intentó emprender una cierta campaña para que se castellanizara no sólo a la aristocracia indígena, como se había hecho hasta entonces, sino que a partir de ese momento debería haber escuelas que enseñaran el español a todos los indios ${ }^{6}$. Con Felipe II, Felipe III y Felipe IV la política osciló entre propiciar la evangelización en lenguas indígenas y usar el castellano.

Sin embargo, a lo largo de los siglos XVi y XVII, los misioneros españoles desobedecieron las leyes venidas de la Península ibérica, porque creían que su misión no tenía por qué consistir en castellanizar a los indios, sino sólo en convertirlos al cristianismo. Los frailes, al observar el éxito de su evangelización en las lenguas vernáculas, se percataron de que éstas eran tanto o más efectivas que el latín o el castellano para adentrar a los indígenas en las cosas de la fe cristiana. Además, la cristianización resultaba más fácil al no tener que imponer, además de una nueva religión, una lengua extraña.

De esta inteligente política evangelizadora y lingüística adoptada por los misioneros españoles se deriva la enorme riqueza de la producción lingüística de la Colonia. Los franciscanos en menos de medio siglo a partir de su llegada, hacia 1570 , escribieron más de ochenta libros sobre las lenguas indígenas, entre gramáticas, vocabularios, catecismos, traducciones de las escrituras, etcétera ${ }^{7}$.

Durante el siglo XVII los misioneros de las diversas órdenes siguieron este mismo camino y continuaron, en muchos casos, ejerciendo su magisterio en las lenguas vernáculas y escribiendo valiosas gramáticas, vocabularios, sermonarios, confesionarios, que constituyen una de las fuentes básicas para el conocimiento histórico de las lenguas indígenas de México $^{8}$.

Un factor que contribuyó al desarrollo y continuidad de estas políticas lingüísticas fue el cambio demográfico. Como es sabido, en el siglo XVı hubo una de las más graves catástrofes demográficas de la historia, que mermó drásticamente a la población indígena mesoamericana. Según cálculos actuales, de una población que en 1519 alcanzaba entre 15 y 25 millones, en 1605 apenas

${ }^{6}$ Véanse Zavala 1977 a y Zavala $1977 \mathrm{~b}$.

${ }^{7}$ Véase Ricard 1933.

${ }^{8}$ Véanse NoRman A. MCQuown, "History of studies in Middle American linguistics", y WILLIAM BRIGHT, "Inventory of descriptive materials". ambos aparecieron en McQUOWn 1967, pp. 3-7 y 9-79 respectivamente. 
superaba un millón. Esto cambió a partir de la segunda mitad del siglo XVII, cuando empezó la recuperación de la población indígena, y continuó durante el siglo XVIII, cuando a fines de siglo, según datos de Humboldt, creció a unos 3700 0009. Esto quiere decir que en el siglo XVIII los indígenas representaban poco más del $60 \%$ de la población total y que, por lo tanto, los hablantes de lenguas indígenas, después de casi dos siglos y a pesar de la catástrofe demográfica inicial, eran más que los hispanohablantes. Fuera de esto, habría que agregar otro factor lingüístico que en el siglo xviII fue determinante. Muchos hablantes bilingües no eran sólo indígenas, sino que los propios españoles que nacían en América, es decir los criollos, aprendían comúnmente desde la cuna una lengua indígena, debido al estrecho contacto que mantenían con sus nodrizas, con las niñeras y, en general, con los sirvientes indios que hablaban sus lenguas nativas.

La primera mitad del siglo XVIII novohispano no sólo fue periodo de crecimiento económico y demográfico ${ }^{10}$, sino también de expansión y desarrollo de las instituciones educativas y de avance científico. Entonces se construyeron grandes e importantes colegios, sobre todo de jesuitas, como el famoso de San Ildefonso en México y otros en varias ciudades del país. Además, los mismos jesuitas abrieron muchas escuelas para niños indígenas en zonas alejadas del norte. La introducción de las misiones y de la educación en las zonas del norte implicó que la investigación lingüística, que desde una perspectiva científica había sido tan productiva, siguiera creciendo y produciendo innovaciones. Del siglo xvIII son una gran parte de las descripciones y vocabularios de las lenguas indígenas del norte del país y varias traducciones a doctrinas cristianas. Muchas de estas obras fueron elaboradas por jesuitas, como los primeros estudios sobre cuatro lenguas yutoaztecas: la lengua cora, que se habla en el actual estado de Nayarit; la cahita, que incluye el mayo de Sinaloa y del sur de Sonora y el

${ }^{9}$ SÁnchez Albornoz 1977, cf. cap. 3.

${ }^{10}$ Según afirma Dorothy Tanck, profunda conocedora del siglo xviII novohispano: "mientras en España prevalecía la crítica del pasado y la duda sobre el futuro, en la Nueva España un ambiente de satisfacción y optimismo permeaba en la sociedad. La Colonia no sólo se había recuperado de la disminución de la población indígena y la crisis minera de las primeras décadas del siglo xVII, sino había consolidado una estructura económica diversificada y autosuficiente", Dorothy Tanck de Estrada, "Tensión en la Torre de Marfil. La educación en la segunda mitad del siglo XVIII mexicano”, en TANCK DE Es. TRADA 1985, p. 27. 
yaqui también del actual estado de Sonora; la lengua ópata, hoy extinguida, y el tepehuán, hablado hoy en los estados de Durango, Chihuahua y Nayarit ${ }^{11}$. Por otra parte, el clero secular criollo contribuyó, junto con las órdenes religiosas, a continuar las labores relacionadas con la descripción de lenguas indígenas y con la traducción de catecismos y doctrinas varias, y empezó también a desempeñar un papel muy importante en las zonas predominantemente indias. Hay que aclarar que, aunque en el siglo XVIII predominó la descripción de las lenguas del norte de México, continuaron haciéndose estudios sobre las lenguas mayoritarias del centro y sur, como el náhuatl y el maya.

Con el advenimiento de los borbones a la monarquía española en el siglo xvıı, se tomaron medidas políticas más vigorosas para obtener mayores beneficios de las colonias. En este contexto, en la Nueva España se dieron dos tipos de reacciones, de sig-

11 Muñoz y Manzano 1892 recoge los siguientes datos sobre la investigación lingüística de los jesuitas en el norte de México: Núm. 298, Vocabulario en Lengua Castellana, y Cora, dispuesto por el P. Joseph de Ortega, de la Compañia de Jesus, Missionero de los Pueblos del Rio de Jesus, Maria y Joseph, de la Provincia de Señor San Joseph de Nayaerit (sic) y visitador de la mesma Provincia. En Mexico: Por los Herederos de la Viuda de Francisco Rodriguez Lupercio, en la Puente de Palacio. Año de 1732. 4, ${ }^{\circ}-9$ hojas preliminares +43 páginas dobles./ Núm. 306, Cathecismo de la Doctrina Christiana traducido en Lengua Cahita. Compuesto por vn Padre de la Compañia de Jesus. Missionero en la Provincia de Cynaloa. En Mexico: por Francisco Xavier Sanchez, en el puente de Palacio. Año de 1737. 8. ${ }^{\circ} 10$ hojas. Icazbalceta: Apuntes, Núm. 86./Núm. 307, Arte de la lengua Cahita, conforme á las Reglas de muchos Peritos en ella. Compuesto por vn Padre de la Compañia de Jesus. Missionero de mas de treinta años en la Provincia de Cynaloa. Año de 1737. Con licencia de los superiores. En México en la Imprenta de D. Francisco Xavier Sanchez, en el puente de Palacio. 8. ${ }^{\circ}-5$ hojas preliminares + otra con fe de erratas +118 páginas + 26 hojas sin numerar que contienen un Vocabulario español-cahita./ Núm. 315, Arte de la Lengua Tepeguana, Con Vocabulario, Confessionario y Cathecismo en que se explican los Mysterios de Nuestra Santa Fé Catholica, Mandamientos de la Ley de Dios y de Nuestra Santa Madre Iglesia. Por el P. Benito Rinaldini, de la Compañia de Jesus, Visitador de la Provincia Tepeguana, y Tarahumara Antigua. Impresso en Mexico (con las Licencias necesarias) por la Viuda de D. Joseph Bernando de Hogal: Calle de las Capuchinas. Año de 1743. 4. ${ }^{\circ}-8$ hojas preliminares + 72 páginas (Arte) + 43 (Catecismo y Confesionario) + 148 (Vocabulario) + 1 hoja de erratas./ Núm. 318, Arte para aprender la Lengua Tepehua$n a$, por el P. Benito Rinaldini, S. J. Mexico, por Joseph Bernardo de Hogal, 1745. - 4. ./ Núm. 352, Doctrina Christiana y Platicas doctrinales, traducidas en lengua Opata por el P. Rector Manuel Aguirre, de la Compañia de Jesus. Impressas en la Imprenta del Real, y mas antiguo Colegio de San Ildefonso de Mexico, año de $1765.4{ }^{\circ}-3$ hojas preliminares +162 páginas +1 hoja de Índice. 
no opuesto entre sí, frente a la política lingüística que deseaban implantar los borbones. La primera reacción se puede ejemplificar con un memorial de 1728, dirigido a Felipe $\mathrm{V}$, que los descendientes de nobles indios presentaron al arzobispo de México, en el que pedían que urgentemente se reabrieran los colegios para indios de Santa Cruz de Tlatelolco y de San Pablo y se estableciera un programa eficaz de enseñanza del español para los indios. Se quejaba de que, a pesar de todos los decretos de España, la mayoría de los indios, ni siquiera los nobles alcanzaran una educación mínima. Por lo tanto, los que no recibían enseñanza,

sólo tienen de racionales lo que les infunde la humana naturaleza, resultando de este tan lastimoso principio hallarse estas pobres miserables gentes, expuestas al vilipendio, pues no instruídas en la vida sociable quedan incapaces de poder ascender al menor puesto, ni tienen en la República algún género de mando [...] [La falta de enseñanza para] los naturales de estos americanos reinos, es sumamente perjudicial no sólo al bienestar de sus individuos, sino también al espiritual aprovechamiento de sus almas y al descargo de la Real Conciencia de su Majestad ${ }^{12}$.

El desconocimiento del español, explicaban los nobles indios al rey, era un hecho muy negativo porque

en estas dilatadas regiones, hay indefinida diversidad de lenguas, y para la inteligencia de cada una, no hay las correspondientes cátedras, resultando de aquí que los naturales en la lengua común del país, o en la castellana, queden sin doctrina, y así envueltos en mil errores e idolatrías, no por otra causa que porque no tienen ministros que se las den a entender y los desengañen ${ }^{13}$.

También hacían ver cómo la fragmentación lingüística de lenguas como el náhuatl impedía que, aunque hubiera enseñanza en esa lengua, ésta no constituyera una solución verdadera, porque:

Aunque tienen los españoles cátedras, sólo son del mexicano idioma y del otomí, las que no son suficientísimas ni aún para hablar la mexicana, por hallarse ésta según la diversidad de los pueblos, donde la hablan con distintas frases, distintas voces y muy confusa en su pronunciación ${ }^{14}$.

12 Velasco Ceballos 1945, pp. 57-58.

${ }^{13}$ Ibid., p. 62.

${ }^{14}$ Loc. cit. 
Las peticiones de la nobleza indígena no tuvieron eco en ese momento y las puertas de los colegios permanecieron cerradas, hasta que, más de cuarenta años después, Carlos III ordenó en 1772 su reapertura.

La segunda reacción contra la política lingüística del setecientos fue radicalmente opuesta. Provenía ésta de los eclesiásticos que habían nacido en la Nueva España y que veían muy negativamente que se enseñara español a los indios, porque el requisito indispensable para obtener una parroquia en las zonas rurales era el conocimiento de una lengua indígena. A los criollos que, como he dicho, por lo general aprendían desde niños la lengua india del lugar donde vivían, no les favorecía que la Iglesia concediera nombramientos parroquiales a los sacerdotes peninsulares que sólo hablaban castellano. Los intereses creados tanto de estos clérigos como de los laicos españoles a quienes beneficiaba mantener alejados y aislados a lo indios llevaron, en ciertos casos, a situaciones extremas de prohibir a los indios hablar el español. Algunos sacerdotes y laicos llegaron a considerar que era una falta de respeto que los indios hablaran español, y cuando éstos lo hacían en su presencia, incluso los castigaban ${ }^{15}$. El mantenimiento del monolingüismo indígena, que llevaba ya dos siglos imponiéndose, era clave para sostener un sistema de estratificación social muy rígido en el que los indios estaban destinados a permanecer siempre en los niveles inferiores de la sociedad.

Como puede observarse, estas posiciones lingüísticas opuestas reflejan brutalmente las contradicciones de los intereses económicos y sociales de la vida novohispana en el siglo xviII. Por un lado, estaban los nobles indios (a quienes hoy desearíamos ver defender la vida de sus lenguas y el desarrollo de sus propias culturas) que, para integrarse en la sociedad dominante, se veían obligados a someterse a los valores europeos, a tal grado de querer olvidar sus rasgos propios. Por otro lado, estaban los criollos, quienes para conservar sus prebendas y privilegios y para seguir desempeñando su papel rector en la sociedad, pretendían conservar intacto el estado de cosas, no por respeto a las culturas y las lenguas indígenas, sino para su beneficio exclusivo frente a los indios, pero también frente a los intereses de los peninsulares. Esta

15 Brice Heath 1972, p. 85. Como ahí se hace notar en la nota 29, es muy convincente el argumento que toma en cuenta el conocimiento de las lenguas indígenas como definitivamente relacionado con las posiciones que desempeñaban criollos y peninsulares; cf. TATE LANNING 1956, pp. 11-13. 
defensa de los derechos y de los intereses criollos más tarde llegaría a ser, en los albores del siglo XIx, uno de los factores determinantes, junto con muchos otros, en las guerras de independencia contra España.

Las reformas borbónicas que se dejaron sentir con mucha fuerza en México en la segunda mitad del siglo xvill contrastaban con las prácticas del xviI, en que las autoridades en América compartían cada vez más el poder con los grupos locales, entre ellos, con la Iglesia, con los cabildos indígenas y con las varias formas de administración coloniales ${ }^{16}$. Las innovaciones borbónicas obedecían a formas de pensamiento y a medidas rígidamente colonialistas que pretendían una mayor sujeción del Nuevo Mundo a la Corona y estaban encaminadas a cancelar la forma de gobierno anterior para imponer otra más centralizadora. La idea del mejoramiento interno de la Nueva España parecía estar ausente ${ }^{17}$. La filosofía política anterior, de la época de los Habsburgo, que había mantenido el principio de que toda sociedad, independientemente de su desarrollo y religión, se rige por leyes naturales, había permitido incorporar a los indios como seres racionales y combinar sus formas de gobierno con las del Imperio español. Por otra parte, como bien dice el historiador colonial Enrique Florescano, al principio de la Colonia, "la idea de que la sociedad se divide naturalmente en partes orgánicas, a las cuales les están asignadas diferentes jerarquías y señalados derechos y obligaciones [...], legalizó la desigualdad social y la diferenciación funcional que se creó en Nueva España inmediatamente después de la conquista" 18 . Pero bajo los Austria ese orden social estaba más controlado por las autoridades virreinales del nuevo continente que por la Corona. En cambio las reformas borbónicas del siglo ilustrado intentaron recuperar los hilos que dentro del virreinato, con independencia de la metrópoli, movían la economía, la política y la administración coloniales. Con los borbones, continúa Florescano, "la nueva España adquirió, en un sentido real y estricto,

16 Todavía en 1716, nos hace ver Dorothy Tanck, el virrey Linares se quejaba de que los novohispanos interpretaran las órdenes reales a su modo y que no adoptaran las resoluciones del Consejo. Textualmente dice el virrey Linares: "Aquí a la voz del mando temen y obedecen poco, y a la del ruego o encargo se ríen y no cumplen nada...". Citado por TANCK DE EsTRADA 1985, de Instrucciones que los virreyes de la Nueva España dejaron a sus sucesores, Imprenta de Ignacio Escalante, México 1873, t. 1, pp. 236, 248.

17 TANCK DE Estrada 1985, pp. 34-35.

18 Florescano y Gil 1976, p. 201. 
su estatus colonial, porque nunca antes su dependencia y sometimiento fueron mayores" 19 .

Nuestro objetivo aquí no es trazar una historia del xvill mexicano, sino únicamente mencionar qué medidas, entre todas las que tomaron los borbones, afectaron la situación lingüística de México. Dorothy Tanck señala en relación con la educación tres decisiones político-religiosas que la afectaron poderosamente y causaron gran descontento entre la población novohispana: "la secularización de las doctrinas de indios; la expulsión de los jesuitas, y el nombramiento de sacerdotes españoles en vez de criollos en las parroquias indígenas" ${ }^{20}$. Estas mismas tres medidas, a mi modo de ver, también afectaron el futuro lingüístico de México; pero a ellas habría que agregar una cuarta que colocó a los indígenas, ya irremediablemente, en una situación de marginación aún mayor de la que tenían. Se trata, como veremos, de la prohibición definitiva del uso de las lenguas vernáculas y de su incorporación obligatoria a la sociedad hispanohablante.

En cuanto a la primera medida, hubo un cambio radical en la política de indoctrinamiento de los indios que hasta entonces había estado en manos de las órdenes religiosas, muy poderosas dentro de la sociedad criolla. En 1749, Fernando VI ordenó a los arzobispados de México y de Lima que se limitara este poder de los frailes y, en 1753, que se secularizaran todas las diócesis de América, para que cada parroquia quedara sujeta a la autoridad del obispo. Con la finalidad de hacer efectivos estos decretos, el arzobispo de México adoptó una política educativa contra la enseñanza en lenguas indígenas, tanto para niños, como para adultos. Entre otras medidas, obligó a las comunidades y pueblos de indios a aportar dinero para la creación de escuelas que enseñaran en español las doctrinas religiosas. Las protestas, e incluso los disturbios, no se hicieron esperar. Los indios se negaban a que sus hijos recibieran educación cristiana en español, porque " sólo en su propio idioma perciben el sentido de las oraciones" y porque la lengua indígena "les paresca más dulze por ser de su $\mathrm{Pa}$ tria, o porque la maman" "21. Ante esta oposición, las autoridades centrales tuvieron que retroceder en su afán de castellanizar a toda velocidad. El fiscal del Consejo de Indias, con sobrada razón, con simpatía y con ironía preguntaba: “¿Cómo se les ha de

19 Ibid., p. 204.

20 TANCK DE Estrada 1985, p. 35.

${ }^{21}$ Ibid., p. 38. 
mandar a los indios que dentro de un año aprendiesen todos el castellano, ya que les sería más dificultoso que el que se les mandase a los españoles aprender el francés?" 22

En cuanto a la segunda medida, la expulsión de los jesuitas, además de que provocó un enorme vacío en la educación de la sociedad colonial ${ }^{23}$, que no nos toca comentar aquí, y que trajo un gran descontento entre amplios sectores de la población, detuvo drásticamente el avance de los estudios lingüísticos, no sólo en la Nueva España, sino en todo el Imperio español. En sus misiones, conforme los jesuitas llegaban a cristianizar tierras nuevas, aprendían y describían la lengua del lugar, al igual que lo habían hecho antes las demás órdenes religiosas, algunas de las cuales continuaban con esa tarea. Esto trajo como consecuencia, repito, que en los siglos coloniales el Imperio español haya sido productivo en extremo en el campo de la lingüística, y que, científicamente hablando, fuera excepcional para su época. Pero, paradójicamente, en el siglo ilustrado, las reformas borbónicas provocaron que, con la expulsión de los jesuitas, este fenómeno se hiciera más lento. Sólo a fines del xVIII, gracias al gran precursor e innovador, al lingüista jesuita español, Lorenzo Hervás y Panduro, se recogerían, para hacer comparaciones sistemáticas datos de todas las lenguas, se tendría por primera vez una visión global de todas ellas y se verían en España los resultados de la enorme riqueza de la investigación lingüística de los siglos coloniales ${ }^{24}$. Sólo en el siglo Xıx, con el desarrollo del comparatismo lingüís-

22 Ibid., p. 39.

${ }^{23}$ Sobre esto, véase Decorme 1941, y Tanck de Estrada 1985. Para la importancia que tuvo el pensamiento de algunos jesuitas en el desarrollo del indigenismo, véase Villoro 1979, esp. el apartado sobre Francisco Javier Clavijero, pp. 95-135.

${ }^{24}$ Lorenzo Hervás y Panduro (1735-1809) es el gran precursor y el iniciador de la lingüística histórica comparada, de carácter científico, que se desarrolló plenamente en el siglo XIX. Cuando en 1767 Carlos III expulsó a los jesuitas, Hervás se trasladó a Roma donde tuvo varios puestos de bibliotecario y donde se dedicó a la tarea de escribir una gran enciclopedia. Parte de ella es el Catalogo delle lingue conosciute e notizia della loro affinità e diversità, Cesena, 1784, ampliado y publicado en español en 1800, bajo el título Catálogo de las lenguas de las naciones conocidas, y numeración, división y clases de éstas según la diversidad de sus idiomas y dialectos, Imprenta de la Administración del Real Arbitrio de Beneficiencia, Madrid, 6 volúmenes. Este Catálogo, además de que constituye la primera visión global de las lenguas mesoamericanas, establece acertadamente varios parentescos entre ellas. El trabajo de recopilación y síntesis elaborado por este jesuita, lingüista por afición, es admirable desde muchos puntos de vista. Como dice Antonio Tovar, Hervás "emprendió una verda- 
tico científico en otros países europeos, como Alemania, Francia e Inglaterra y en algunas de las naciones recién liberadas de América, especialmente los Estados Unidos y México, se recuperó y aprovechó la abundancia y la variedad de las descripciones lingüísticas de la Colonia y continuaron haciéndose nuevos estudios. Sin embargo, en España, con la excepción de Hervás y Panduro, pareció olvidarse por largo tiempo este tipo de investigaciones lingüísticas ${ }^{25}$, hasta que, a fines del siglo xIx, el Conde de la Viñaza elaboró una excelente bibliografía sobre las lenguas vernáculas del nuevo continente, donde se describen las aportaciones científicas de España al conocimiento de las lenguas de América ${ }^{26}$.

Sobre la tercera reforma, es decir, el nombramiento de peninsulares a parroquias americanas, ya hemos visto cómo los intereses de los curas criollos chocaban con los de los españoles. Sólo agregaremos aquí que conforme avanzó el siglo fueron más frecuentes las medidas de la Corona para recuperar y centralizar su autoridad, dando apoyo a los peninsulares. Entre tanto, aumentaba el descontento hacia la Corona, los curas criollos bilingües que perdían su poder, veían reducidas sus prebendas y sentían que no se les reconocía como súbditos útiles y que se ignoraban sus aportaciones al bienestar de los reinos.

Por último, el intento más perdurable de castellanizar a toda la población se dio en el reinado de Carlos III, cuando ya los jesuitas habían sido expulsados. El arzobispo de México, Antonio Lorenzana y Buitrón, ante la rivalidad creciente entre los religio-

dera encuesta [lingüística] oral aprovechando la concentración en los Estados Pontificios [...] de muchísimos jesuitas procedentes de los países más diversos [...] con práctica de años en América, Oceanía, etc.", Tovar 1986, p. 14. Seguramente consultó, además, muchas de las obras que hasta entonces se habían publicado, y probablemente copias manuscritas de otras que se editaron más tarde, pero que eran de consulta frecuente. Hervás pensaba que las lenguas son la clave de la historia, y que su conocimiento daría luz sobre los diversos pueblos de la tierra. Hay que destacar que Guillermo de Humboldt, el iniciador formal del comparatismo lingüístico historicista, conoció la obra de Hervás publicada en italiano y aprovechó muchos de sus materiales. Además, la obra también comparatista muy consultada de Johann Christoph Adelung y Johann Severin Vater, Mithridates oder allgemeine Sprachekunde mit dem Vater Unser als Sprachprobe in bey nähe fünf hundert Sprachen und Mundarten, 18061817, está basada, en gran parte, en los datos de la fuente italiana de Hervás, véase Tovar 1986, pp. 24-25.

${ }^{25}$ Para una visión general, pero muy clara, ilustradora y profunda de cómo se desarrolló la lingüística dentro de la Península ibérica durante el siglo XviII, incluida la labor de Hervás y Panduro, véase LÁZaro Carreter 1985.

${ }^{26}$ Cf. supra, nota 11. 
sos que estaban a favor de la castellanización y los que estaban en contra, alertó a Carlos III en 1768 para que tomara medidas que resolvieran la conflictiva situación. En octubre de 1769, Lorenzana publicó una Pastoral $^{27}$ en la que exponía cuál era la situación lingüística de la Nueva España, cuáles las ventajas de la castellanización masiva y cuáles las desventajas de que persistieran la enseñanza y las prédicas religiosas en las lenguas vernáculas. Explicaba que la enorme gama de lenguas que se hablaba en la Nueva España no sólo dificultaba la enseñanza, sino también el control que la Iglesia debía tener sobre los indios y sobre sus propios ministros. Escribe Lorenzana:

Deseamos, pues, que las Ovejas entiendan la voz, y silbo común de los pastores, no que éstos se acomoden precisamente a el balido vario de las Ovejas: el Obispo es el primer Párroco, y mayor de todos los Párrocos, y ni entiende, ni puede entender tan diversos Idiomas en su Diócesis ${ }^{28}$.

En sus argumentos, Lorenzana trataba de convencer a Carlos III de que en la historia de la humanidad no había habido imperio que no impusiera su lengua a los sometidos. Consideraba que el empleo de intérpretes para tratar con los indios contribuía a que éstos estuvieran sujetos a una explotación que se había vuelto crónica; además, conforme se iban colonizando nuevas regiones, los traductores se volvían insuficientes. Según el arzobispo de México, las lenguas indígenas propiciaban el aislamiento de los indios que vivían encerrados en sus pequeñas aldeas sin poderse comunicar unos pueblos con otros, ante lo cual Lorenzana concluía que la incomunicación fomentaba en ellos el temor y el aborrecimiento hacia los españoles. Por otra parte, el prelado pensaba que los eclesiásticos habían descuidado la educación general de los indios por tener que ocuparse del multilingüismo, lo cual le parecía que sólo beneficiaba a los clérigos bilingües que, por practicar en idiomas extraños, se salían del control de la Iglesia.

En resumen, para Lorenzana y Buitrón la situación era muy

${ }^{27}$ Velasco Ceballos 1945, pp. 71-80. Además de la recopilación antológica de Velasco Ceballos en la que me baso, hay una edición antigua a la que no he tenido acceso de las Cartas Pastorales y edictos del ilustrisimo señor D. Francisco Antonio Lorenzana y Buitrón, Arzobispo de México. Impresas con licencia. En México, en la imprenta del Superior Gobierno, del Br. D. Joseph Antonio de Hogal, 1770.

${ }^{28}$ Velasco Ceballos 1945, p. 77. 
compleja e inmanejable, y en lo político se estaba volviendo caótica. Dice:

El mantener el Idioma de los Indios es capricho de Hombres, cuya fortuna, y ciencia se reduce a hablar aquella Lengua, que también la aprende un Niño; es contagio, que aparta a los Indios de la conversación de los de los Españoles; es peste, que inficiona los Dogmas de Nuestra Santa Fé; es arbitrio perjudicial para separar los Naturales de unos Pueblos de otros por la diversidad de Lenguas; es gasto crecido para los Párrocos, que en su mismo Partido necesitan Ministros de distintos Idiomas; es imposibilidad para el Gobierno de los Obispos, para la división de Curatos, para el premio de los Españoles, e Indios decentes, honrados, bien educados, y beneméritos; es poner un Alcalde mayor entre Gentes, que ni le entienden, ni las entiende como si estuviera en Grecia, o Berbería; es ocultar los errores de los Naturales, para que los Superiores no les corrijan; es dar motivo a que no formen concepto de la Divina Magestad, ni de la del Rey... ${ }^{29}$

La respuesta de Carlos III no se hizo esperar. El 16 de abril de 1770, el monarca, aconsejado también por el marqués de Croix, virrey de la Nueva España, emitió una cédula, "Para que en los reynos de las indias, islas adyacentes y de Filipinas, se pongan en práctica y observen los medios que se refieren y ha propuesto el arzobispo de México, a fin de conseguir que se destierren los diferentes idiomas de que se usa en aquellos dominios, y solo se hable el castellano" 30 .

Carlos III pretendía poner fin a todos los males que le decían que provocaba el mutilingüismo: la necesidad de intérpretes, la falta de comprensión hacia los sacerdotes, los conflictos entre clérigos criollos y españoles, la deficiencia de la educación de los indígenas, la falta de imposición de las medidas que tomaba la Corona, etc. El deseo de Carlos III por resolver la compleja situación de sus colonias, por imponer la hegemonía de la Corona y, al mismo tiempo, por mejorar el modo de vida y la educación de los indios, está presente en toda la cédula. El rey creía que con estas medidas:

Los indios no quedarían tan expuestos a ser engañados en sus tratos, comercios o pleitos; los Párrocos estarían más uniformes; los colegiales de tantas Comunidades respetuosas de aquellos Dominios,

29 Ibid., p. 78.

${ }^{30}$ Ibid., p. 81 . 
lograrían el premio de sus desvelos, y con la emulación crecería el adelantamiento; y toda la tierra podría gobernarse con más faci$\operatorname{lidad}^{31}$.

Finalmente, Carlos III instaba a todas las autoridades, civiles y religiosas, a los

Virreyes del Perú, Nueva España y Nuevo Reyno de Granada, a los Presidentes, Audiencias, Gobernadores y demás Ministros, Jueces y Justicias de los mismos Distritos y de las Islas Philipinas y demás adyacentes; [...] que desde luego se pongan en práctica y observen los medios que van expresados y ha propuesto el mencionado Muy Reverendo Arzobispo de México, para que de una vez se llegue a conseguir el que se extingan los diferentes idiomas de que se usa en los mismos Dominios, y sólo se hable el Castellano, como está mandado por repetidas leyes, Reales Cédulas y Órdenes expedidas en el asunto ${ }^{32}$.

Las protestas no tardaron y los clérigos que trabajaban en las aldeas indias levantaron denuncias contra las medidas de la Corona. Por otra parte, en México, el nuevo virrey, Antonio María Bucareli, temió que la política del rey causara fuertes disturbios en la sociedad novohispana, y se dedicó a aplicar tácticas dilatorias y ha hacer todo lo posible por entorpecer, tanto la castellanización masiva, como la apertura de colegios para instruir a los indios, que el rey había ordenado en $1772^{33}$. A pesar de que Carlos III emitió nuevos decretos en 1774, 1776 y $1778^{34}$, el virrey hizo todo lo posible por obstaculizar las reales órdenes ${ }^{35}$.

Mientras tanto, a los intelectuales criollos que deseaban modernizar la educación, el problema del multilingüismo y de la enseñanza en lenguas vernáculas no parecía preocuparles gran cosa. Ellos ocupaban toda su energía en criticar las anticuadas prácticas educativas escolásticas y en imitar los mejores y más modernos modelos de enseñanza de lenguas que practicaba la nobleza euro$\mathrm{pea}^{36}$. Además, a medida que el castellano adquiría mayor prestigio gracias a la fundación de la Real Academia Española en 1713,

31 Ibid., p. 85.

32 Ibid., pp. 85-86.

33 BRice Heath 1972, p. 87

${ }^{34}$ Loc. cit.

${ }^{35}$ Sobre el gobierno del virrey Bucareli, véase Bовв 1962.

${ }^{36}$ Esta actitud puede observarse en publicaciones de la época que tenían gran influencia sobre los intelectuales de México, en especial puede verse la 
a la publicación entre 1726 y 1739 de su Diccionario de Autoridades, a la edición de su Gramática en 1771 y de su Diccionario usual en 1780 , las capas más altas de la sociedad novohispana también presionaron con gran fuerza para que la única lengua del virreinato fuera el español, y para que el ideal y la norma lingüísticos no fueran los dialectos hispánicos locales que estaban desarrollándose, sino exclusivamente la lengua que se hablaba en Castilla, tal como la codificaba la Real Academia.

A pesar de la lentitud y de la dificultad con la que se aplicaban las medidas de Carlos III y gracias a la indiferencia de la elite criolla hacia el problema lingüístico indígena de América ${ }^{37}$, la castellanización fue poco a poco ganando terreno. Con el paso del tiempo, a pesar de la voluntad eclesiástica y misionera de continuar utilizando las lenguas indígenas, en la práctica se fue imponiendo cada vez más el español, de modo que ya en la época de la Independencia los gobiernos liberales, que buscaban una educación igualitaria, pudieron implantar, de manera definitiva, una educación en español para toda la población. Los distintos gobiernos que se sucedieron en adelante, durante más de un siglo, se desentendieron del problema lingüístico de los indígenas, a pesar de que lo indio empezaba a considerarse como una de las bases de la nacionalidad. No fue sino hasta muy entrado el siglo xx, cuando el estado mexicano, a fines de los años treinta, durante el gobierno de Lázaro Cárdenas, volvió los ojos de nuevo hacia los indios al intentar que se les diera a los niños indígenas el derecho elemental de ser alfabetizados en su propia lengua materna.

\author{
Beatriz Garza Cuarón \\ El Colegio de México
}

revista que dirigía José Antonio Alzate, la Gaceta de Literatura, que se publicó entre 1788 y 1795 .

${ }^{37}$ Los avances en la enseñanza del español llegaron a ser muy considerables, incluso desde un punto de vista técnico. Por ejemplo, Carlos III, en un decreto de 1768 había recomendado para la enseñanza del español el texto de Juan de Iriarte. Este texto fue el que sustituyó en gran medida a la gramática de Nebrija, e incluso tuvo influencia en la enseñanza de lenguas europeas entre la elite novohispana. Para los métodos de enseñanza que se emplearon con los índigenas, véase Ruiz de Bravo Ahuja 1977. 


\section{BIBLIOGRAFÍA}

Aguirre Beltrán, Gonzalo 1983. Lenguas vernáculas. Su uso y desuso en la enseñanza: la experiencia de México. Centro de Investigaciones y Estudios Superiores en Antropología Social, México.

Bahner, Werner 1966. La lingüistica española del Siglo de Oro. Ciencia Nueva, Madrid.

Bobs, Bernard E. 1962. The Viceregency of Antonio Maria Bucareli in New Spain, 1771-1779. University of Texas Press, Austin.

Brice Heath, Shirley 1972. La política del lenguaje en México: de la Colonia a la Nación. Instituto Naeional Indigenista, México.

Decorme, Gérard 1941. La obra de los jesuitas mexicanos durante la época colonial. Robredo, México.

Florescano, Enrigue, e Isabel Gil Sánchez 1976. "La época de las reformas borbónicas y el crecimiento económico, 1750-1808", en Historia General de México. T. 2. El Colegio de México, México.

Lázaro Carreter, Fernando 1985. Las ideas lingüísticas en España durante el siglo xviii. Crítica, Madrid. [I ${ }^{\mathrm{a}}$ ed., 1949].

Manrique, Leonardo (ed.) 1988. Atlas cultural de México: Lingüistica. Secretaría de Educación Pública-Instituto Nacional de Antropología e HistoriaPlaneta, México.

McQuown, Norman A. (ed.) 1967. Handbook of Middle American Indians. T. 5: Linguistics. University of Texas Press, Austin.

Muñozy Manzano, Cipriano (Conde de la Viñaza) 1892. Bibliografía española de lenguas indígenas de América. Sucesores de Rivadeneyra, Madrid.

Nebrija, Antonio de 1984. Gramática de la lengua castellana. $2^{a}$ ed. Ed. y est. de Antonio Quilis. Editora Nacional, Madrid.

Ricard, Robert 1933. La "conquête spirituelle" du Mexique. Institut d'Ethnologie, Paris.

Ruiz de Bravo Ahuja, Gloria 1977. La enseñanza del español a los indígenas mexicanos. El Colegio de México, México.

SÁnchez Albornoz, Nicolás 1977. La población en América Latina desde los tiempos precolombinos al año 2000. Alianza Editorial, Madrid.

Tanck De Estrada, Dorothy 1985. Ensayos sobre historia de la educación en México. $2^{\mathrm{a}}$ ed. El Colegio de México, México.

Tate Lanning, John 1956. The Eighteenth-Century Enlightenment in the University of San Carlos de Guatemala. University of Cornell Press, Ithaca.

Tovar, Antonio 1986. El lingüista español Lorenzo Hervás. Sociedad General Española de Librería, Madrid.

Velasco Ceballos, Rómulo 1945. La alfabetización en la Nueva España. Secretaría de Educación Pública, México.

Villoro, Luis 1979. Los grandes momentos del indigenismo mexicano. Eds. de La Casa Chata, Instituto Nacional de Antropología e Historia, México. [ $1^{\text {a }}$ ed., El Colegio de México, México, 1950].

Zavala, Silvio 1977a. ¿El castellano, lengua obligatoria? Secretaría de Educación Pública, México. [Una versión más amplia en Condumex, México, 1977].

Zavala, Silvio 1977b. "El castellano, ¿lengua obligatoria? Adiciones", $M e^{-}$ moria de El Colegio Nacional, 8, núm. 4, 141-162. 